STAVOVI PREMA

MENTALNO OBOLELIM

U CRNOJ GORI:

ADAPTACIJA CAMI SKALE

\author{
Ljubomir Žiropađa $^{1}$ \\ Andrija Dulović ${ }^{2}$
}

\section{Kratak sadržaj}

Uvod: Podaci o stavovima prema mentalno obolelim osobama u Crnoj Gori prilično su oskudni. Razloge za to treba tražiti u činjenici da istraživači nemaju na raspolaganju proverene instrumente. Polazeći od skale stavova prema mentalno bolesnim koju su razvili Martin Tejlor i Majkl Dir (CAMI) napravljena je crnogorska verzija ove skale.

Cilj rada: Istraživanje je sprovedeno s namerom da se na uzorku crnogorske populacije ispitaju osnovna svojstva modifikovane CAMI skale, proveri njena višedimenzionalnost i utvrde demografski korelati tih dimenzija.

Metod rada: Dvesta osamdeset i sedam ispitanika starih između 17 i 84 godina, iz više crnogorskih mesta, popunjavalo je upitnik sa CAMI skalom stavova prema mentalno obolelim. Njihovi odgovori su podvrgnuti postupku ekstrakcije glavnih komponenti. Uticaj nekih demografskih varijabli (pola, obrazovanja, uzrasta) i dužeg kontakta sa mentalno obolelim osobama na stav prema mentalno bolesnim procenjivan je postupkom stepenaste regresije..

Rezultati: Analiza glavnih komponenata (nakon Varimax rotacije) vodi zaključu o postojanju pet dimenzija u stavovima prema osobama koje su lečene od mentalnih bolesti: uvažavanje ljudskih prava obolelih i odbacivanje njihove stigmatizacije, distanciranje od mentalno obolelih, pozitivan odnos prema ideji komunalne psihijatrije, isticanje potrebe za blagonaklonim odnosom i tolerancijom i autoritarni odnos. Ovih pet faktora objašnjavalo je 43\% ukupne varijanse. Koeficijent unutrašnje konzistentnosti cele skale (Kronbahov alfa) iznosio je 0,87. Pol (ženski) i duži kontakt sa mentalno obolelima bili su prediktori pozitivnijeg stava prema mentalno obolelima, dok je efekat obrazovanja bio slabo izražen.

Zaključak: Ova skala stavova prema mentalno obolelim osobama može se koristiti u daljim istraživanjima na crnogorskoj teritoriji. Buduća istraživanja treba da se usredsrede na ispitivanje stabilnosti faktorske strukture skale, kao i na uticaj kolektivističkih vrednosti na stavove prema mentalno obolelim.

Ključne riječi: Deinstitucionalizacija, CAMI, predrasude, stigma

2 Trenkwalder outsourcing, Podgorica, Montenegro 


\section{UVOD}

Lečenje mentalno obolelih osoba izvan tradicionalnih psihijatrijskih institucija jedan je od glavnih ciljeva politike u oblasti mentalnog zdravlja. Ostvarenje tog cilja zavisi od sveobuhvatne podrške zajednice, okruženja koje omogućava mentalno obolelima da uživaju sva gradanska prava kao i mentalno zdravi i od tolerancije i nediskriminatorskog ponašanja u zajednici [1]. Važnost razvijanja pozitivnijih stavova prema mentalno obolelima ogleda se i u tome što negativni stavovi okoline povećavaju stres i umanjuju kvalitet života mentalno obolelih, što umanjuje efikasnost njihovog deinstitucionalnog tretmana [2]. Borinstajn [3] navodi da je deinstitucionalizacija prešla put od stvarnog i uglavnom skrivenog društvenog problema do problema koji se iznosi široj publici. Specifičan otpor građana SAD deinstitucionalizaciji mentalno obolelih označen je kao „ne u mom dvorištu“. Ovaj autor navodi da su u delu ispitivanja koje je imalo za cilj da ispita poželjnost postojanja određenih institucija u naseljima ustanove za mentalno obolele označene kao najmanje poželjne.

Istraživanja stavova prema mentalno obolelima ukazala su na značaj određenih demografskih karakteristika za valencu stava prema ovim pacijentima. Mada nije reč o jakim prediktorima, ipak se neke demografske varijable u većem broju istraživanja pojavljuju kao statistički značajni korelati negativnog stava prema mentalno obolelima. Negativniji stav ispoljavaju starije osobe [4 - 7], manje obrazovane i iz nižih društvenih slojeva [4, 5, 8 - 10]. Negativni stav je takođe nešto češći kod muškaraca [11 - 13]. Često se u ovim istraživanjima pokazuje da osobe koje imaju manje znanja o mentalnim bolestima i manje neposrednih kontakata sa mentalno obolelim osobama ispoljavaju negativnije stavove [2]. Međutim, čak i kada je reč o osobama koje profesija vezuje za pomaganje mentalno bolesnim licima zadržava se negativan, stigmatizirajući i diskriminatorski stav prema takvim pacijentima [14]. U tim slučajevima se ne može pretpostaviti da je reč o efektu nedovoljnog znanja ili odsustva kontakta.

$\mathrm{Za}$ ispitivanje stavova prema mentalno obolelima u kvantitativnim istraživanjima i utvrđivanje korelata tih stavova često se koristi CAMI skala (Community Attitude towards Mentally Ill scale) [15]. Konstruktori ove skale stavova prema mentalno obolelima smatraju da ona procenjuje četiri dimenzije stava prema mentalno obolelima: 1) autoritarno odbacivanje obolelih (shvatanje da su mentalno bolesni manje vredna bića i isticanje potrebe za njihovom hospitalizacijom i strogim nadzorom nad njima, shvatanje da su bolesnici odgovorni za svoje probleme i dr.); 2) blagonaklon odnos (isticanje potrebe da se usmeri više sredstava za pomoć obolelima, rezervisanost prema grubim merama usmerenim na prismotru mentalno obolelih i dr.); 3) distanciranje od mentalno obolelih (nespremnost da se uđe u bliže odnose s osobama koje su bile ili jesu mentalno obolele, shvatanje da su oni opasni za društvo i dr.) i 4) prihvatanje ideologije komunalne psihijatrije, koja za osnovni cilj ima da mentalno obolela lica što kraći period provedu u zatvorenoj instituciji i da se kompletna terapija i rehabilitacija sprovodi u njihovom neposrednom životnom okruženju, tj. u zajednici. Ovaj faktor se odnosi na različita uverenja da se većini mentalno obolelih može pružiti pomoć i bez hospitalizacije, kao i na isticanje terapijske uloge svakodnevnog društvenog okruženja. 
Činjenica da u crnogorskoj sredini nema puno istraživanja o stavovima prema mentalno obolelima bila je podsticaj da se sprovede ovo istraživanje. Ono je imalo za cilj da se ispitaju svojstva CAMI skale, njena multidimenzionalnost, kao i da se utvrde demografski korelati tih dimenzija i značaj kontakta sa mentalno obolelima za valencu stava prema mentalno bolesnim osobama.

\section{METOD}

\section{Uzorak i postupak istraživanja}

Uzorak je bio prigodnog tipa i njime je obuhvaćeno 287 ispitanika iz više mesta u Crnoj Gori (Podgorica, Nikšić, Bar, Danilovgrad, Kolašin). Ispitano je 153 žena i 129 muškaraca, za 5 anketiranih nedostajao je podatak o polu. Prosečna starost ispitanika bila je 40,03 godine. Najmlađi ispitanik je imao 17 godina, a najstariji 84 . Najveći broj ispitanika (58\%) imao je završenu srednju školu, dok je 37\% imalo višu ili visoku školsku spremu. U celini gledano, uzorak je u pogledu nivoa obrazovanja odstupao od obrazovne strukture crnogorske populacije. Prema podacima Zavoda za statistiku Crne Gore, u popisu stanovništva iz 2011. godine bilo je $28 \%$ onih sa osnovnom i nepotpunom osnovnom školom, $52 \%$ onih sa završenom srednjom školom, $17 \%$ onih sa višom ili visokom školom po novom i starom sistemu obrazovanja, dok je 3\% bilo bez škole ili bez odgovora [16]. Očigledno, učesnici u našem istraživanju bili su nešto obrazovaniji i nisu reprezentativni za crnogorsku populaciju, ali to nije smetnja za osnovne ciljeve ovog istraživanja.

Ispitanici su bili anketirani individualno u svojim kućama ili u svojoj radnoj sredini u periodu mart-april 2011. godi- ne. Anketiranje su obavili studenti odseka za psihologiju Filozofskog fakulteta u Nikšiću.

\section{Instrumenti istraživanja}

Korišćen je upitnik koji se sastojao od dva dela. Prvi deo je činila CAMI skala stavova prema mentalno obolelim osobama. Stavke originalne skale su prevedene i donekle modifikovane kako bi bile prilagođene crnogorskoj populaciji. Autori originalne CAMI skale su kombinovali Upitnik uverenja o mentalnoj bolesti i Upitnik za ispitivanje ideologije komunalne psihijatrije. Skala ima 40 stavki i odgovori se zahtevaju po Likertovom modelu (1=uopšte se ne slažem, $2=$ ne slažem se, $3=$ niti se slažem niti se ne slažem, 4=slažem se i $5=$ sasvim se slažem). Istraživanja sprovedena u svetu pokazuju da ova skala u punom obimu ima prihvatljiv nivo unutrašnje konzistentnosti - Kronbahov alfa koeficijent se kreće od 0,68 do 0,88 [2]. Drugim delom upitnika prikupljeni su demografski podaci. Traženi su sledeći podaci o ispitaniku: starost, pol, školska sprema (u godinama školovanja), kao i informacija o tome da li je nekada bio u dužem kontaktu sa mentalno obolelom osobom iz porodice ili neposredne društvene okoline. Oko polovine anketiranih $(47,4 \%)$ izjavilo je da je imalo duži kontakt sa nekom mentalno obolelom osobom (iz svoje porodice ili neposredne društvene okoline), što je još jedan indikator odstupanja uzorka od reprezentativnog.

\section{Obrada podataka}

Za obradu podataka korišćen je statistički softver SPSS, verzija 17. Utvrđivanje dimenzionalnosti skale stava prema men- 
Tabela 1: Rezultati analize CAMI skale metodom glavnih komponenata sa Varimaks rotacijom (pet komponenti objašnjava 43\% ukupne varijanse).

Table 1: Community Attitudes to Mental Illness in Montengro. Results of PCA with Varimax rotation (five principal components explain $43 \%$ of the total vatiance).

\section{Zasićenja:}

Loadings:

Prva komponenta: Uvažavanje ljudskih prava i odbacivanje stigmatizacije

First component: Respect for the human rights of patients and rejection of their stigmatization

Duševno bolesne treba što više uključivati u normalan život.

Mental patients should be encouraged to assume the responsibilities of normal life.

Smještanje duševno oboljelih u „ludnice” je zastario način liječenja.

Mental hospitals are an outdated means of treating the mentally ill.

Skoro svako može oboljeti od duševne bolesti.

Virtually anyone can become mentally ill.

Niko nema prava da duševno oboljele izoluje od ostalog svijeta.

No one has the right to isolate the mentally ill from the rest of the community.

Duševno bolesne osobe treba izdvojiti od normalnih.

The mentally ill should be isolated from the normal.

Našem društvu je potreban tolerantniji stav prema duševno bolesnim licima.

Our society needs to adopt a far more tolerant attitude toward the mentally ill in our society.

Duševne bolesti su kao i sve druge bolesti.

Mental illness is an illness like any other.

Ljudi treba manje da se plaše duševnih bolesnika.

People have less to fear the mentally ill.

Pomoć duševnim bolesnicima, što je više moguće, treba pružati u običnim domovima zdravlja.

As far as possible mental health services should be provided through community-based facilities.

Druga komponenta: Distanciranje od mentalno bolesnih

Second component: Distance towards the mentally ill

Ženi je najpametnije da se ne udaje za muškarca koji je liječen od neke duševne bolesti, čak i kad se čini da se on potpuno oporavio.

A woman would be foolish to marry a man who has suffered from mental illness, even

though he seems fully recovered.

Duševno bolesnoj osobi možemo povjeravati odgovorne poslove.

Mentally ill person can be assigned to responsible jobs.

Mada zadržavanje duševnog bolesnika u njegovoj sredini može biti dobro za njega,

rizik za njegove susjede je veliki.

Having mental patients living within their community might be good therapy, but the

risk to residents is too great.

Ne bih želio/la da za prvog komšiju imam nekoga ko je duševno obolio.

I would not want to live next door to someone who has been mentally ill.

Čim se primijete znaci duševne bolesti, bolesnu osobu treba smjestiti u bolnicu za duševno oboljele.

As soon as a person shows signs of mental disturbance, he should be hospitalized.

Najbolje je izbjegavati osobu koja ima duševnu bolest.

It is best to avoid anyone who has mental problems.

Većini žena koje su nekad bile liječene od duševne bolesti mogu se povjeriti djeca na čuvanje.

Most women who were once patients in a mental hospital can be trusted as babysitters.

Duševnim bolesnicima je potrebna ista ona kontrola i disciplina koja je potrebna i maloj djeci.

Mental patients need the same kind of control and discipline as a young child. 
Državne poslove nikako ne bi trebalo povjeravati onima koji su nekada liječeni od neke duševne bolesti.

Anyone with a history of mental problems should be excluded from taking public office.

Duševni bolesnici su mnogo manje opasni nego što se to vjeruje.

The mentally ill are far less of a danger then most people suppose.

Treća komponenta: Prihvatanje ideja psihijatrije u zajednici

Third Componet: Community Mental Health Ideology

Stanovnici treba da se suprotstave izgradnji objekata namijenjenih duševno bolesnim u njihovoj stambenoj četvrti.

Local residents have good reason to resist the location of mental health services in their neighborhood.

Građani treba da prihvate gradnju bolnice za duševne bolesnike u svom susjedstvu.

Residents should accept the location of mental health facilities in their neighborhood.

Bolnica za duševne bolesnike u stambenoj zoni ugrožava stanovnike.

Locating mental health hospital in residential neighborhood endangers local residents.

Ustanove za pomoć duševno oboljelim treba da se grade izvan stambenih četvrti.

Mental health facilities should be kept out of residential neighborhoods.

Smještanje neke ustanove za duševno oboljele u neki kraj grada, čini taj kraj

neprivlačnim za stanovanje.

Placing an institution for the mentally ill in some part of town, makes it unattractive to housing.

Stanovništvo ne treba da se plaši ako u blizini njihovog mjesta stanovanja postoji neka ustanova koja pruža pomoć duševnim bolesnicima.

Residents should not be afraid if near their places of residence there is a mentall health facility.

Zastrašujuća je pomisao da ljudi sa duševnom bolešću žive u tvom susjedstvu.

It is frightening to think of people with mental problems living in residential

neighborhoods.

Četvrta komponenta : potrebe za blagonaklonim odnosom i tolerancijom

Fourth component: Tolerance and sympathetic attitude towards mentally ill

Suviše novca se troši na liječenje duševno oboljelih.

Less money should be spent on the care and treatment of the mentally ill.

Duševne bolesnike ne treba odbacivati.

The mentally ill should not be rejected.

Kod nas se duševno bolesnim osobama pruža dovoljno pomoći i pažnje.

Our society provides enough support and attention to mentally ill.

Više novca treba uložiti u brigu i liječenje duševno oboljelih

More money should be spent on the care and treatment of the mentally ill. .

Duševne bolesnike previše potcjenjuju i izlažu podsmijehu.

The mentally ill have for too long been the subject of underestimation and ridicule.

Duševnim bolesnicima NE treba uskraćivati njihova ljudska prava.

The mentally ill should not be denied their individual rights.

Naše bolnice za duševno bolesne više liče na zatvore nego na bolnice koje se staraju o

svojim bolesnicima.

Our mental hospitals seem more like prisons than like places where the mentally ill can

be cared for.

Peta komponenta: Autoritarni odnos

Fifth Component: Authoritarian relation

Duševno bolesnim osobama nedostaje disciplina i snaga volje. Mentally ill lack self-

discipline and will power.

Duševno bolesne osobe zaslužuju naše saosjećanje.

The mentally ill deserve our sympathy.

Duševno bolesne je lako razlikovati od normalnih osoba.

There is something about the mentally ill that makes it easy to tell them from normal people.

Duševni bolesnici su teret za ovo društvo.

The mentally ill are a burden on society. 
talno obolelim obavljeno je analizom glavnih komponenti sa Varimaks rotacijom. Stepenasta multipla regresiona analiza korišćena je da bi se utvrdili značajni korelati stava prema mentalno obolelim iz skupa demografskih varijalbli.

\section{REZULTATI}

Za celu skalu je bilo moguće izračunati ukupan skor za procenu stava prema mentalno obolelima na način koji je uobičajen za skale Likertovog tipa i vodeći računa o tome da li stavka iznosi uverenje protiv ili u prilog mentalno obolele osobe.

U ovom istraživanju Kronbahov alfa koeficijent za punu skalu iznosio je 0,87 , što odgovara vrednostima koje su dobijene u studijama izvedenim u drugim sredinama.

Analiza skale ekstrakcijom glavnih komponenata s ortogonalnom Varimaks rotacijom i primenom Kajzerovog kriterijuma pružila je osnov za zaključak o sledećih pet dimenzija korišćenog instrumenta: 1) uvažavanje ljudskih prava obolelih i odbacivanje njihove stigmatizacije, 2) distanciranje od mentalno obolelih, 3 ) pozitivan odnos prema ideji komunalne psihijatrije, 4) isticanje potrebe za blagonaklonim odnosom i tolerancijom i 5) autoritarni odnos. Stavke koje imaju najviša zasićenja na ovim dimenzijama prikazane su u tabeli 1.

Nakon utvrđivanju faktorske strukture skale pristupilo se stepenastoj multiploj regresionoj analizi sa ukupnim skorom na CAMI skali i faktorskim skorovima koji odgovaraju prethodno opisanim komponentama kao zavisnim varijablama, i demografskim atributima i dužim kontaktom s licem obolelim od neke mentalne bolesti kao prediktorima. Rezultati su pri- kazani u tabeli br. 2 i vode sledećim osnovnim zaključcima.

1. Pol i kontakt sa mentalno obolelima javljaju se kao statistički značajni prediktori ukupnog skora na CAMI skali. Žene su iskazivale ukupno pozitivniji stav prema mentalno obolelim osobama. I muškarci i žene koji su imali duže kontakte sa mentalno obolelima imali su pozitivniji stav prema mentalnoj bolesti. Zanimljivo je da nivo obrazovanja nije imao znatnijeg uticaja na iskazivanje pozitivnijeg stava prema mentalno bolesnim osobama.

2. Starost i pol su se javili kao statistički značajni prediktori faktorskih skorova koji odgovaraju prvoj komponenti CAMI skale. Žene i mlađi ispitanici iskazivali su više uvažavanja prema ljudskim pravima obolelih i manju sklonost ka stigmatizaciji.

3. Distanciranje od mentalno obolelih (druga komponenta CAMI skale) bilo je izrazitije kod starijih i kod muškaraca.

4. Raniji bliži kontakt sa mentalno obolelim osobama bio je jedini prediktor pozitivnog odnosa prema ideji komunalne psihijatrije (treća komponenta CAMI skale).

5. Mlađi i obrazovaniji ispitanici češce su isticali potrebu za blagonaklonim odnosom i tolerancijom prema mentalnim bolesnicima (četvrta komponenta CAMI skale).

6. Nijedan od korišćenih prediktora nije bio u korelaciji sa faktorskim skorom autoritarnog stava prema mentalno obolelima. 


\section{DISKUSIJA}

Ovim istraživanjem su ispitana svojstva CAMI skale na crnogorskom uzorku. Faktorskom analizom (metoda glavnih komponenti sa Varimaks rotacijom) izdvojeno je pet faktora. Pored četiri faktora koja su utvrđena u istraživanju konstruktora skale, u našem istraživanju je izdvojen i faktor uvažavanja ljudskih prava obolelih i odbacivanje njihove stigmatizacije.

Od obuhvaćenih demografskih varijabli, pol se pokazao kao značajan prediktor ukupnog skora na CAMI skali. Žene su imale pozitivniji opšti stav prema mentalno obolelim osobama: iskazivale su više uvažavanja prema ljudskim pravima mentalno obolelih i manju sklonost ka stigmatizaciji, dok su muškarci imali veći skor na faktoru distanciranja od mentalno obolelih. Ovi nalazi su u skladu sa većinom ostalih istraživanja $[2,11-13,17]$ Vrlo retko se dešava da se ne dobije ovakav odnos između rodne pripadnosti i faktora CAMI skale [6]. Treba, međutim, ukazati i na jednu specifičnost rezultata koji su dobijeni ovim istraživanjem. Muškarci su pokazali veću distanciranost prema mentalno obolelim (druga kompo-

\begin{tabular}{|c|c|c|c|c|c|}
\hline \multicolumn{6}{|c|}{$\begin{array}{c}\text { Tabela 2: Rezultati stepenaste multiple regresione analize: prediktori su pol, starost, } \\
\text { obrazovanje i kontakti sa mentalno obolelim } \\
\text { Table 2: Results of stepwise regression analysis: gender, age, education and contact } \\
\text { with the metally ill were predictors }\end{array}$} \\
\hline $\begin{array}{l}\text { Zavisna varijabla } \\
\text { Dependent variable }\end{array}$ & $\mathbf{R}$ & $\mathbf{F}$ & $\begin{array}{l}\text { Prediktori } \\
\text { Predictors }\end{array}$ & B & $\mathbf{t}$ \\
\hline $\begin{array}{l}\text { Ukupan skor } \\
\text { Overall CAMi score }\end{array}$ & 0,27 & $11,10^{* *}$ & $\begin{array}{l}\text { Pol }(0=\text { muški, } \\
1=\text { ženski }) \\
\text { Gender }(0=\text { male, } \\
1=\text { female }) \\
\text { Kontakt } \\
\text { Contact }\end{array}$ & 0,12 & $4,34^{* *}$ \\
\hline $\begin{array}{l}\text { Prva komponenta } \\
\text { First component } \\
\text { (factor score) }\end{array}$ & 0,22 & $6,87 * *$ & $\begin{array}{l}\text { Starost } \\
\text { Age } \\
\text { Pol } \\
\text { Gender }\end{array}$ & $\begin{array}{l}-0,01 \\
0,31\end{array}$ & $\begin{array}{l}-3,04 * * \\
2,62 * *\end{array}$ \\
\hline $\begin{array}{l}\text { Druga komponenta } \\
\text { Second component } \\
\text { (factor score) }\end{array}$ & 0,26 & $5,95^{*}$ & $\begin{array}{l}\text { Starost } \\
\text { Age } \\
\text { Pol } \\
\text { Gender }\end{array}$ & $\begin{array}{l}0,01 \\
-0,29\end{array}$ & $\begin{array}{l}3,49 * * \\
-2,62 *\end{array}$ \\
\hline $\begin{array}{l}\text { Treća komponenta } \\
\text { Third component } \\
\text { (factor score) }\end{array}$ & 0,13 & $4,84^{*}$ & $\begin{array}{l}\text { Kontakt } \\
\text { Contact }\end{array}$ & 0,28 & $2,20^{*}$ \\
\hline $\begin{array}{l}\text { Četvrta komponenta } \\
\text { Fourth component } \\
\text { (factor score) }\end{array}$ & 0,25 & $6,23^{*}$ & $\begin{array}{l}\text { Starost } \\
\text { Age } \\
\text { Obrazovanje } \\
\text { Education (years) }\end{array}$ & $\begin{array}{l}-0,01 \\
0,16\end{array}$ & $\begin{array}{c}-3,05^{* *} \\
2,50 *\end{array}$ \\
\hline $\begin{array}{l}\text { Peta komponenta } \\
\text { Fifth component } \\
\text { (factor score) }\end{array}$ & 0,11 & $<1$ & - & - & - \\
\hline
\end{tabular}

$* * \mathrm{p}<0,01 * \mathrm{p}<0,05$ 
nenta), ali u strukturi ove komponente značajnu ulogu ima strah, za koji se na osnovu niza postojećih istraživanja može pretpostaviti da je izraženiji kod žena [18]. Zato smatramo da je neophodno u narednim istraživanjima proveriti stabilnost faktorske strukture skale.

Direktni kontakt sa mentalno obolelim osobama takođe se pokazao kao značajan i nezavisan prediktor ukupnog pozitivnog stava prema mentalno obolelima. Prethodni kontakt sa mentalno obolelima bio je značajno povezan sa pozitivnim stavom prema ideji komunalne psihijatrije. Ovi nalazi su u poptunom skladu sa zaključcima drugih istraživača $[2,6]$.

Naše istraživanje je pokazalo da mlađi ispitanici iskazuju više uvažavanja prema ljudskim pravima obolelih i manju sklonost ka stigmatizaciji, kao i da češce iskazuju potrebu za blagonaklonim odnosom prema mentalno obolelima. Nasuprot njima, stariji ispitanici su više težili distanciranju od mentalno obolelih. I ovi rezultati su u najvećem delu saglasni s onima dobijenim u inostranim istraživanjima $[2,5$ $-7,17]$.

Sasvim neočekivano, obrazovanje se nije pokazalo kao značajan prediktor opšteg stava prema mentalno obolelima. Korišćeni uzorak je imao sniženu varijabilnost u pogledu obrazovnog nivoa isptanika i ta restrikcija opsega mogla je dovesti do ovakvog ishoda. Ipak, obrazovaniji crnogorski ispitanici pokazivali su su nešto veću sklonost ka blagonaklonom odnosu i toleranciji mentalno obolelih (četvrta komponenta), što je dobijeno i u nekim inostranim istraživanjima [6].

Mada su, u studijama ovog tipa, uzrast i obrazovanje najčěćci korelati autoritarnog stava prema mentalno obolelima, u našem istraživanju nisu se pokazali kao uspešni prediktori.
U celini gledano, modifikacija CAMI skale pokazala se kao upotrebljiv instrument za ispitivanje stavova prema mentalno obolelim u crnogorskoj sredini. Koeficijent unutrašnje homogenosti, dimenzionalnost skale i podaci o demografskim korelatima stava procenjenog pomoću ove skale, to potkrepljuju. Činjenica je, međutim, da su korelati relativno slabi prediktori opšteg stava prema mentalno obolelim i to u svim njenim dimenzijama (mada su dostigli konvencionalne nivoe statističke značajnosti). Ovo upućuje na potrebu da se u narednim analizama obrati pažnja ne samo na stabilnost faktorsek strukture, već i na činioce koji nisu bili obuhvaćeni ovim istraživanjem. U prvom redu to su: 1) indirektni kontakt i načini obaveštavanja o metalnim bolestima i obolelima, i 2) privrženost kolektivističkim vrednostima.

Poznato je da je za pozitivniji stav prema mentalno obolelima značajan i indirektan kontakt, a ne samo neposredan. Rezultati jednog američkog istraživanja pokazuju da su izvori informacija o mentalno obolelima najčešće televizija (87\%), zatim novine $(76 \%)$, časopisi $(74 \%)$, radio $(73 \%)$, porodica ili prijatelji $(51 \%)$ i knjige $(50 \%)$ [3]. U meri u kojoj se u navedenim medijima manje potkrepljuje strah od mentalno obolelih i smanjuje otpor prema učešću u brizi o mentalno obolelima, smanjuje se stigmatizacija obolelih [19].

U narednom istraživanju bi svakako bilo potrebno da se ispita uticaj prihvatanja kolektivističkih vrednosti na stav prema mentalno obolelim. Poznato je da su u kolektivističkim kulturama ljudi zavisniji od grupa kojima pripadaju (porodice, plemena, nacije itd.) i svoja ponašanja zasnivaju prvenstveno na grupnim normama. U literaturi postoje procene položaja jed- 
nog broja savremenih kulturnih zajednica na dimenziji kolektivizam-individualizam [20]. Očekivano, na toj listi ne postoji Crna Gora, ali se ipak može zaključiti da savremeno crnogorsko društvo pripada krugu kolektivističkih kultura. Unutar ove osnovne dimenzije moguće je napraviti dodatne podele (na primer, na osnovu toga u kojoj meri poštuju postojeću hijerarhiju u društvenim odnosima i dr.), ali je ipak najznačajnija ova podela na individualističke (u kojima su pojedinci samostalniji i daju prednost ispunjavanju sopstvenih ciljeva i ideala) i kolektivističke kulture. Prema nekim podacima, u individualističkim kulturama, kao što su nemačka, australijska, britanska ili anglosaksonska severnoamerička, manja je stigmatizacija osoba sa telesnim i psihičkim poremećajima [21 -23]. Jedno skorašnje istraživanje [24] pokazuje da je stigmatizacija mentalno obolelih izraženija kod državljana Velike Britanije koji svojim poreklom pripadaju kolektivističkim kulturama (Grci i Kinezi). Mada naše istraživanje nije sprovedeno sa namerom da se izvrše specifična poređenja sa podacima dobijenim u individualističkim kulturama, moglo bi se ukazati da je $25 \%$ engleskih ispitanika (pripadnici individualističke kulture) saglasno sa tim da se ženama koje su lečene od mentalnih bolesti mogu poveriti deca na čuvanje, dok je u našem uzorku samo $8,9 \%$ ispitanika saglasno sa tom tvrdnjom. Možda se obra- zovanje javlja kao slab prediktor stava prema mentalno obolelim kod naših ispitanika zbog premoći kolektivističkih vrednosti.

\section{ZAKLJUČAK}

Stigmatizacija mentalno obolelih u Crnoj Gori ima dugu istoriju i obuhvata shvatanja o uzrocima bolesti, prirodi bolesti, načinima lečenja i ophođenju prema mentalno obolelima [25]. Problem prevazilaženja stigmatizacije mora biti važan deo društvene i zdravstvene politike, a ujedno i kliničke prakse. Kao načine za prevazilaženje stigmatizacije mentalno obolelih, Pejović-Milovančević i sar. [26] navode reformisanje ustanova, predstavljanje anti-diskriminatornih zakona i politika, edukaciju osoba koje pružaju negu, upotrebu medijskih kampanji uz praćenje i obuku novinara i programe za unapređenje znanja i veština u oblasti mentalnog zdravlja, ali ističu da je opšti stav da se samo kombinovanim pristupom, kojim bi se uticalo i na društvene ustanove i organe, može postići značajan rezultat.

$\mathrm{Da}$ bi se ispitalo u kojoj meri su postignuti željeni rezultati, neophodno je raspolagati valjanim instrumentom za procenjivanje stava prema mentalno obolelim. Verujemo da naše istraživanje pokazuje da se u te svrhe može koristiti adaptacija CAMI skale koju smo opisali u ovom članku. 


\section{ATTITUDES TOWARDS MENTALLY ILL \\ IN MONTENEGRO:T \\ HE MONTENEGRIN \\ VERSION OF CAMI}

\author{
Ljubomir Žiropađa ${ }^{1}$ \\ Andrija Dulović ${ }^{2}$
}

1 Faculty of Philology, Belgrade University

2 Trenkwalder outsourcing, Podgorica, Montenegro

\section{Summary}

Introduction: Data about the general public's attitude towards people with serious mental illness in Montenegro are scarce. A possible reason for this situation may lie in the fact that local researchers, in contrast to researchers elsewhere, have not at their disposal reliable instruments that could measure attitudes toward mentally ill people. Building on Taylor \& Dear's development of the Community Attitudes towards Mental Illness scale (CAMI) we present a modified version of CAMI.

Objective: The aim of this study was to examine the properties of the scale, to describe the dimensions of attitudes toward the mentally ill, and to identify demographic correlates of these dimensions.

Method: Two hundred and eighty seven adults aged 17 years and above (range 17 to 84 ) completed the Montenegrin version of Community Attitudes toward the Mentally Ill. Their answers were analyzed by principal component analysis. Impact of contact with mentally disturbed person, age, education, and gender on attitudes towards mentally ill was assessed by stepwise regression analysis.

Results: Pricipal component analysis with Varimax rotation revealed five components which account for $43 \%$ of the total variance: 1) Respect for the human rights of patients and rejection of their stigmatization, 2) Distance towards the mentally ill, 3) Positive attitude towards the idea of psychiatry in the community, 4) Tolerance and sympathetic attitude towards mentally ill, and 5) Authoritarian attitude. The coefficient of internal consistency (Cronbach's alpha) of CAMI was 0.87. Gender (female) and prolonged contact with the mentally ill were associated with a more favourable attitude towards the mentally ill, but, unexpectedly, education level was weak predictor of positive attitude.

Conclusion: There is a correspondence between the Montenegrin version and the original version of the CAMI. Further research should test replicability of the CAMI factor-structure, and focus on the impact of collectivist values on attitudes towards the mentally ill.

Key words: deinstitutionalization, CAMI, prejudice, stigmatization 


\section{Literatura:}

1. Hannigan, B. Mental health care in the community: an analysis of contemporary public attitudes towards, and public representations of, mental illness. J Ment Health 1999; 5:431-40.

2. Song L-Y, Chang L-Y, Shih C-Y, Lin C-Y, Yang M-J. Community attitudes towards the mentally ill: the results of a national survey of the Taiwanese population. Int J Soc Psychiatry 2005; 2:162-76.

3. Borinstein AB. Public attitudes toward persons with mental illness. Health Aff 1992; 3:186-96.

4. Brockington IF, Hall P, Levings J, Murphy $C$. The community's tolerance of the mentally ill. Br J Psychiatry 1993; 162:93-9.

5. Clark AW, Binks NM. Relation of age and education to attitudes toward mental ilIness. Psychol Rep 1966; 19:649-50.

6. Wolff G., Pathare S, Craig T, Leff J. Community attitudes to mental illness. $\mathrm{Br} \mathrm{J}$ Psychiatry 1996; 168:183-90.

7. Wolff G., Pathare S, Craig T, Leff J. Community knowledge of mental illness and reaction to mentally ill people. Br J Psychiatry 1996; 168:191-8.

8. Murphy BM, Black P, Duffy M, Kieran J, Mallon J. Attitudes towards the mentally ill in Ireland. Ir J Psychol Med 1993; 10:75-9.

9. Heller PL, Chalfant H, Rivera-Worley M, Quesada G., Bradfield, C. Socio-economic class, classification of "abnormal" behaviour and perceptions of mental health care: $A$ cross-cultural comparison. Br J Med Psychol 1980;. 4:343-8.

10. Whatley CD. Social attitudes toward discharged mental patients. Soc Probl 1959; 6:313-20.

11. Farina A. Are women nicer people than men? Sex and the stigma of mental disorders. Clin Psychol Rev 1981; 1:22343.
12. Morrison M., de Man AF, Drumheller A. Correlates of socially restrictive and authoritarian attitudes toward mental patients in university students. Social Behav Pers 1993; 21:333-8.

13. Morrison M, de Man AF, Drumheller A. Multidimensional locus of control and attitudes toward mental Illness. Percept Mot Skills 1994; 3:1281-2.

14. Wahl OF, Aroesty-Cohen E. Attitudes of mental health professionals about mental illness: A review of the recent literature. J Community Psychol 2010; 38:49-62.

15. Taylor MS, Dear MJ, Hall G.B. Attitudes toward the mentally ill and reactions to mental health facilities. Soc Sci Med 1979; 130:281-90.

16. Zavod za statistiku Crne Gore. Obrazovna struktura stanovništva Crne Gore 2012. [internet]. [cited 2013 Mar 22]. Available from: http://www.monstat.org/userfiles/file/popis2011/Saop_obraz\%2014_06_2012_ \%20konacno\%20PDF.pdf

17. NHS Information Centre, Mental Health and Community. Attitudes to Mental Illness - 2011 survey report. [internet]. [cited 2013 Mar 22]. Available from: https://catalogue.ic.nhs.uk/publications/mental-health/legislation/atti-ment-illn-2011/attiment-illn-2011-sur-rep.pdf

18. Ewalds-Kvist B, Högberg T, Lützén K. Impact of gender and age on attitudes towards mental illness in Sweden. Nord $\mathrm{J}$ Psychiatry 2013; 67:360-368.

19. Wahl OF. News media portrayal of mental illness: Implications for public policy. Am Behav Sci 2003; 46:1594-600.

20. Hofstede, G.. Culture's consequences: Comparing values, behaviors, institutions, and organizations across nations (2nd ed.). Thousand Oaks: Sage Publications; 2001. 
21. Jacques ME, Linkowski DC, Sieka FL. Cultural attitudes toward disability: Denmark, Greece and the United States. Int J Soc Psychiatry 1970; 16:54-62.

22. Papadopoulos C, Leavey G., Vincent C. Factors influencing stigma: A comparison of Greek-Cypriot and English attitudes towards mental illness in north London. Soc Psychiatry Psychiatr Epidemiol 2002; 9:430-4.

23. Westbrook ML, Legge V, Pennay M. Attitudes towards disabilities in a multi-cultural society. Soc Sci Med 1993; 5:615-23.

24. Papadopoulos C, Foster J, Caldwell K. 'Individualism-Collectivism' as an explanatory device for mental illness stigma. Community Ment Health J 2013; 3:270-80.
25. Dulović A. Tradicionalne predstave o mentalno oboljelim osobama u Crnoj Gori. Sociološka luča 2011; 2:112-20.

26. Pejović-Milovančević M, Pavlović M, Toševski-Lečić D, Tenjović LR. Promena diskriminativnog i negativnog stava prema mentalnim bolestima kod školske dece. Nastava i vaspitanje 2005; 1:89-98.

Ljubomir Žiropađa

Filološki fakultet, Studentski trg 3

11000 Beograd

$0112630-873$

ziropadja@fil.bg.ac.rs 